\title{
Some Recommended Correction Techniques for ESL Learners' Writing
}

\author{
Xiaotong Zeng \\ The University of Sheffield, Western Bank, Sheffield S10 2TN
}

\begin{abstract}
As the most time-consuming and labor-intensive part of ESL teacher work, correction on students' writing has received a great deal of attention in recent decades. In terms of how to maximize the positive effect of teacher correction, researchers hold differing opinions such as comprehensive/unfocused correction, selective/unfocused correction, direct correction, indirect correction and so on. In this essay, the author will recommend two ways, namely, selective/unfocused correction and a combination of indirect correction and direct correction, which are supported by some pieces of soundly designed empirical research and second language acquisition theories.
\end{abstract}

Keywords: ESL, Teacher correction, Selective/focused, Direct, Indirect.

\section{Introduction}

In teaching English as a second language, offering correction and feedback on learners' written contexts is the most time-confusing and exhausting teacher responsibility; yet whether it can have actual positive effect on improving learners' writing capability is still in suspense. Thus, even in recent years, the debate on whether teachers should provide written correction on students' writing has never come to an end. And if the answer for the question is positive, which types of written correction are the best for writing improvement constitute another controversial event. Within a variety of correction strategies (direct correction, indirect correction, selective/focused correction, comprehensive/ unfocused correction, metalinguistic corrective feedback and so on), I recommend two strategies, namely, focused/selective correction, and a combination of indirect and direct correction.

\section{Selective/Focused Correction}

According to Sheen, Wright and Moldawa (2009), "the unfocused approach involves correction on a wide range of errors in each piece of students' written texts, while a focused approach can be achieved by selecting a specific grammatical problem that teachers have observed in their students' writing and directing the $\mathrm{CF}$ (corrective feedback) at just this feature for a limited period of time" (p. 559). What I want to supplement here is that focused correction is not only selective in terms of the number of grammatical errors picked up, but also in the three key dimensions of an essay, namely, linguistic accuracy, content and organization.

The following is an example of focused correction and the sample comes from a first-year high-school student in China:

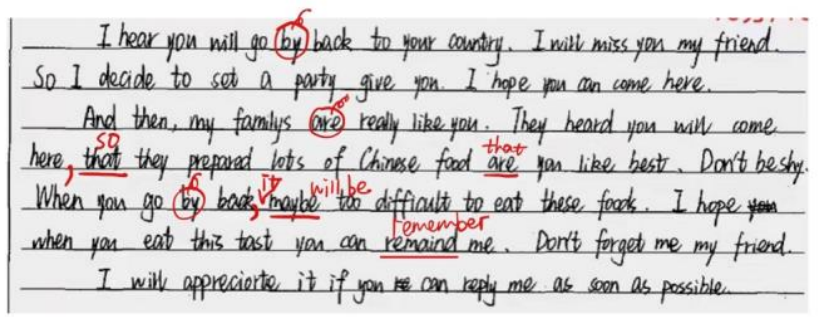

There have been some pieces of research carried out advocating the use of focused correction. And here I want to introduce two of them. The first study is Sheen (2007) in which 111 intermediate-level learners mainly from three language backgrounds (Korean, Hispanic and Polish) that are divided into two experimental groups and one control group are involved. In the study, the researcher only focuses on one linguistic feature which is English articles. And one of the conclusions is that "written CF targeting at a single linguistic feature improved learners' accuracy" (Sheen 2007: p. 255). Here this correction technique is regarded as a focused one in two senses. First, instead of providing correction on all key writing dimensions (linguistic accuracy, content and organization), only one dimension, language, is paid attention. Second, among a range of grammatical features, only one feature, article, is corrected. Just as summarized by Sheen (2007), this highly focused type of written CF is proved to be effective in increasing students' grammar accuracy. The second study in favor of focused correction is Sheen, Wright and Moldawa (2009), investigating the effectiveness of focused correction and unfocused correction by adult ESL learners. In this study, the participants are 5 native-English speaking teachers and 80 intermediate-level students in a US college and they are divided into one control and three experimental groups. The study proves the absolute superiority of focused correction over the unfocused one in the writing of L2 English learners by showing that "the Focused CF group outperformed the Control group and by failing to demonstrate any benefit in providing unfocused CF" (Sheen, Wright and Moldawa 2009: p. 567). Also, according to the researchers, three points are responsible for the superiority of the focused correction: a. making students be sensitive to not only the errors being corrected but also other grammatical features, in other words, attending to the form of language; $b$. involving a systematic and non-arbitrary way of correction; c. utilizing explicit and taught metalinguistic knowledge to help students increase accuracy. Besides, in the study, the risks of using unfocused correction are presented: a. confusing students by offering students with unsystematic and inconsistent correction; b. overburdening students by correcting all errors in writing.

Compared with unfocused/comprehensive correction which is arbitrary, confusing and inconsistent, focused/selective correction is a systematic approach in that writing teachers usually pay attention to those errors that are the most serious 
or affect comprehensibility of students' writing texts.

Regarding to my personal experience, this approach is highly applicable in China, especially in middle schools and high schools. As the students in China's middle and high schools are occupied by heavy workload consisting of six subjects (Math, Chinese, English, Physics, Chemistry, Biology, Politics, History, and Geography) per day, most of them cannot spend a lot of time revising and correcting all the errors in the writing texts marked by English teachers. What's worse, some students who see that their papers are full of red ink here and they may feel so disappointed and frustrated that they will just throw away the feedback provided by teachers without even a glance. Thus, it is of great necessity for the teachers to find a correction approach that will not only indeed help students improve writing but also not discourage or demotivate students. I think that focused correction is the one that can fulfill the goal. By consulting the teaching syllabus, teachers can point out the errors that are considered as key points or the errors that repeatedly appear. In this case, such correction technique not only reduces teachers' workload but also boosts students' learning enthusiasm. In addition, if teachers adopt a process-oriented approach involving multiple drafts to teach writing, focused correction is also applicable. They may choose to focus on and respond to content and organization of compositions systematically in the first and second drafts, and in the final draft, they can primarily attend to linguistic accuracy to help students produce more accurate and mature works.

What's more, I would like to prove the effectiveness of focused correction from the view of second language acquisition. There is a point in Polio (2012: p. 384): "The feedback has to be at the right developmental level for the learner". Also, in the essay, Polio (2012) argues that according to the sociocultural theory which is one of the research fields in second language acquisition, the type of feedback should be tailored to cater to the learner's individual needs; and that according to the interactionist theory, "one of the factors related to learning is the learner's level, which will affect his or her ability to pay attention to the feedback" ( $p$. 384). As a result, it is not recommended to respond to L2 students' writing comprehensively. In the area of SLA, a well-known theory is that only when the learner feels mentally ready to pick up the language point, can the knowledge be acquired by the learner. This tells us that if the writing teacher corrects a student's errors in a scattershot manner and includes a lot of grammatical features in one time when the student does not feel ready to acquire, in other words incapable of processing, then the correction is mostly ineffective. Therefore, it will be better that the teacher only chooses and corrects the errors that are suitable to the student's current proficiency level, which is what we call selective correction. Besides, in view of attentional resources, focused correction is better than unfocused correction. Polio (2012) proposes that "the learner has to pay attention to the feedback" (p. 385). However, it is claimed that "attentional resources are limited and that to attend to one aspect of performance (complexity of language, accuracy, fluency) may well mean that other dimensions suffer" (Skehan 1998, cited in Skehan 2003: p. 5). Thus, to maximize the effect of correction, teachers ought to select and prioritize the most serious or global grammatical errors or the most significant writing dimension (linguistic accuracy, content and organization) to attract students' attention in a bid to promote writing improvement.

To sum up, selective/focused correction is a feedback type featured by being systematic and consistent. Rivers argues that "to be effective, systematic training in writing requires systematic correction of individual scripts" (Rivers 1968: pp. 255-56, cited in Lalande II 1982: p. 140), indicating that writing teachers shall utilize the technique of focused/ selective correction rather than the unfocused/comprehensive one. Even taking the amount of work done by both teachers and students into consideration, focused correction is more recommended because it is far less overwhelming than the unfocused approach.

\section{A Combination of Indirect Correction and Direct Correction}

In accordance with Ferris and Roberts (2001), "direct feedback is given when the teacher provides the correct form for the student writer, and if the student revises the text, s/he needs only to transcribe the correction into the final version; indirect feedback occurs when the teacher indicates in some way that an error exists but does not provide the correction, thus letting the writer know that there is a problem but leaving it to the student to solve it" (pp. 163-164). As Bitchener and Knoch (2009) exemplify, "direct correction may include the crossing out of an unnecessary word/phase/morpheme, the insertion of a missing word/phrase/morpheme, or the provision of the correct form or structure" (p. 323); while in indirect correction, students cannot depend on teachers offering explicit correction, but instead they shall refer to reference materials to make correction on their own.

The following are examples of direct correction and indirect correction that I found in Chandler (2003).

$$
\begin{aligned}
& \text { "I am from Saudi Arabia but I am American. My father had tork there for five } \\
& \text { years } 1 \text { also went there with him," she said very slowly. I understood a few } \\
& \text { words, "father,"American," five years" and'I." I had to guess ther whole time. I said } \\
& \text { that I didn't understand the first time but I didn't understand fine most onthings she } \\
& \text { said to I I just moved my head like I knew what she was saying }
\end{aligned}
$$

Direct correction (Chandler 2003: p. 282)

Every day at four-fifty, you would see something magical happened. The building still looked_ordinary as usual, but it seemed to radiante some kind of incantation that the people from all kinds of building in the huge school suddenly spilled out their building and flowed to it as natural as the water goes to the lower place. The building just like becoming a magnet in a sudden and the people_like the spreaded iron sands which attached to it instantly.

Indirect correction: underlining (Chandler 2003: p. 283) 


\author{
"Mayu, would you go to the tofu shop and get two pieces of tofu?" \\ It was my first try to go to any store by myself. \\ "Me? Can I do it? Mmm.... It sounds too difficult for me." \\ ww/art "No, it is easy. The tofu you need to take is called silk tofu._Only thing you \\ insent need to do is to ask them, "Could you give me two pieces_tofu?" That's it." \\ wW/insert "O.K. If I say, 'Could you give me two pieces of tofu,' do they give me?" \\ punc "No_ you should say, 'silk tofu'."
}

Indirect correction: underlining and describing (Chandler 2003: p. 282)

After referring to a number of research papers illustrating the respective merits of direct correction and indirect correction, here I propose that writing teachers should combine the direct and indirect approaches; however, indirect correction should play the major role and direct correction a supplemental role. Many pieces of research (Bitchener and Knoch 2009, Ferris and Roberts 2001) mention that indirect correction can nurture students' problem-solving and self-learning abilities by guided-learning, which are the ultimate goal of learning. I think this is the superiority of the indirect approach, though it is not very suitable for beginning or lower-level L2 learners, in that this approach sets a sustainable development path for students in the long term. In terms of students of lower levels, direct correction, of course, is more appropriate. As mentioned in Bitchener and Knoch (2009), direct correction reduces students' confusion and non-understanding caused by teachers' implicit correction (like coding, underlining) and by their poor knowledge base; "provides learners with sufficient information to resolve more complex errors (for example, errors in syntactic structure and idiomatic usage); and provides learners with more immediate feedback on hypotheses that they have made" (p. 323). Nevertheless, these lower-level students will gradually evolve to a more proficient level, and then the indirect approach should come on the stage to foster their independence in writing and correcting writing. Speaking of the studies in favor of my view, Lalande (1982) is the one that presents the absolute advantage of indirect correction. The experiment, designed to test the effectiveness of indirect correction and direct correction on the "grammatical correctness and orthographic correctness of compositions written by intermediate-level college students studying German" (p. 141), was conducted in 1979 at Pennsylvania State University, involving sixty students that are divided into two groups (a control group and an experimental group). The thirty students in the control group are offered with all corrections by teacher and "required to incorporate the same in a re-written version" (Lalande 1982: p.141); while the thirty students in the experimental group are given Error Correction Code (a way of indirect correction) and "required to correct errors according to the codes and then rewrite the same essay" (Lalande 1982: p.143). At last, the results show that the students in the experimental group perform significantly better than their counterparts in the control group, indicating that indirect correction outperforms the direct one in this context. Lalande (1982) proposes that the indirect approach raises students' error awareness and inspires their problem-solving ability, thus, producing positive effects on their writing skills. Besides, an implication on teaching writing is given: "students should correct their own grammatical and orthographic errors wherever possible" (Lalande 1982: p. 147), which advocating the crucial position of indirect correction.

Chandler (2003) is a piece of research that supports both direct correction and indirect correction. The second study of this research, aiming to test the effects of four different kinds of teacher response to students' texts (direction correction, underlining with description of error type, description of error type, and simple underlining), involves 36 students of the same course taught in the same way by the same teacher. All participants receive four types of teacher responses as mentioned above in different orders, and the outcome measures include "number of errors per 100 hundred (accuracy); holistic ratings of overall writing quality; time spent on writing (fluency); immediate student feedback to each correction type; a rough comparison of time that the teacher spent giving each type of correction" (Chandler 2003: p. 281). The results show that direct correction facilitates significant improvement in accuracy; at the same time, underlining (indirect correction) has almost the same effect on accuracy as the direct one. Apart from the accuracy increase, students' reaction to and comment on different types of correction are also considered. While a vast majority of students regard the direct approach as the easiest way to correct errors because the explicit correct forms are directly and immediately provided by the teacher, there are still half of them deeming Underlining with Description (also a kind of indirect correction) as helpful for long-term writing development (Chandler 2003). One of the students comments that the Correction method (referred to the direct method) is the easiest to correct "'because you've already written the correct answers for us' and therefore she liked it best because it took less time" (p. 288). Also, this student feels that indirect correction (underlining) improves the problem-solving ability and enhances her memory about the errors because: "I can look up for the correct answers by myself, and this makes easier to remember the mistakes I made so I won't do it again"” (p. 289). In view of the student's opinion, both direct and indirect corrections have their respective advantages and are beneficial to learners depending on the goals (like accurate and time-saving correction or learning-guided correction).

Just as proposed by Chandler (2003), the advantage of direct correction lies in that all errors can be corrected soon after students complete the essays and receive feedback from teachers, without struggling to test their hypotheses that they make if they are given indirect correction where errors are merely underlining without any correct forms. In this sense, direct correction is the easiest and time-saving way, particularly for lower-level students (especially beginners) and the students who cannot spare too much time for writing correction due to heavy course load. Also, in terms of some complicated grammar points or structures, the direct approach is recommended as it can reduce students' confusion. However, indirect correction is equipped with unignorable strength which is promoting self-learning ability. As aforementioned, providing indirect correction is a kind of guided-learning which means that students, referring to the cues (underlining errors) provided by teachers, make efforts to get the correct forms by consulting authoritative materials, reflecting on previous notes and self-editing. Making students look for and discover the correct form is more instructive to them because it gives students a sense of participation, thus, motivating them. Lalande II (1982) also mentions that indirect 
correction helps learners build their problem-solving ability which opens a window for them to reconstruct and refresh their knowledge base. This can actually facilitate the acquisition and internalization of the errors they made.

Perhaps some people may oppose to indirect correction by arguing that it imposes negative impact on students' attitudes and writing fluency. However, according to the second study of Chandler (2003), such negative effect does not exist. There is even a student giving such comments: "I think if I can have Underline and Describe or Underline but not just correction, I'll feel more helpful. Just Describe I need long time to correct; only Correction I feel I can't learn them and I don't feel participate" (Chandler 2003: p. 292). The student's comments well suggest that direct or indirect correction alone cannot have the maximum effect on writing improvement.

As a matter of fact, both direct correction and indirect correction are effective in reducing errors. Direct correction is the best for producing accurate revisions and provides the time-saving advantage for both learners and teachers. Indirect correction is the best for learners, especially intermediate and proficient ones, to gradually develop problem-solving capacity. As a consequence, indirect correction and direct correction should work together and supplement each other depending on different situations (grammar complexity, students' levels, students' time devoted to correction and so on) in teacher response to students' writing texts. Also, I think that, to some extent, indirect correction ought to take more proportion in teacher response because the lower-level learners will definitely make progress throughout the learning process and eventually they will grow to higher-level learners and even proficient ones. Nurturing their learning independence shall begin as earlier as possible so as to obtain a lasting positive effect in subsequent learning stages.

\section{Conclusion}

In the context of second/foreign language learning, teacher response in writing is complex. The discussions on whether written corrective feedback has positive influence on student writing and on which types of written corrective feedback can help learners achieve the greatest improvement are unstopping. The two correction techniques, namely, focused correction, and combination of indirect correction and direct correction, that I recommend here are the two ways which I believe can maximize the positive effect of teacher response on the basis of the studies to date because they take a variety of factors such as the underlying theories like second language acquisition, learner feelings, and teaching contexts into account. In conclusion, while writing teachers are responding to students' writing, what they need to bear in mind is that correction, no matter focused or unfocused, direct or indirect, shall serve the students' original communicative intent (Chandler 2003), which is to help students to better express their ideas and thoughts in essays.

\section{References}

[1] Bitchener, John, and Ute Knoch. 2009. "The Relative Effectiveness of Different Types of Direct Written Corrective Feedback", System (Linköping), 37.2, 322-29
[2] Chandler, Jean. 2003. "The Efficacy of Various Kinds of Error Feedback for Improvement in the Accuracy and Fluency of L2 Student Writing", Journal of Second Language Writing, 12.3, 267-96

[3] Ellis, Rod, and others. 2008. "The Effects of Focused and Unfocused Written Corrective Feedback in an English as a Foreign Language Context", System (Linköping), 36.3, 353-71

[4] Ferris, Dana, and Barrie Roberts. 2001. "Error Feedback in L2 Writing Classes: How Explicit Does It Need to Be?", Journal of Second Language Writing, 10.3, 161-84

[5] Ferris, Dana R., and John S. Hedgcock. 2014. "Teaching L2 Composition : Purpose, Process, and Practice, Third edition", New York: Routledge, Taylor \& Francis Group.

[6] Lalande II, John F. 1982. "Reducing Composition Errors: An Experiment", The Modern Language Journal (Boulder, Colo.), 66.2, 140-49

[7] Polio, Charlene. 2012. "The Relevance of Second Language Acquisition Theory to the Written Error Correction Debate", Journal of Second Language Writing, 21.4, 375-89

[8] Sheen, Younghee. 2007. "The Effect of Focused Written Corrective Feedback and Language Aptitude on ESL Learners' Acquisition of Articles", TESOL Quarterly 41.2, 255-283

[9] Sheen, Younghee, David Wright, and Anna Moldawa. 2009. "Differential effects of focused and unfocused written correction on the accurate use of grammatical forms by adult ESL learners", System (Linköping), 37.4, 556-569

[10] Skehan, Peter. 2003. "Task-Based Instruction", Language Teaching, 36.1, 1-14 